\title{
ATIVIDADE ANTAGONISTA DE Bacillus subtilis SOBRE DOIS ISOLADOS DE Fusarium solani DO MARACUJAZEIRO, POR DIFERENTES MÉTODOS
}

\section{Geraldo Gomes Rocha Sobrinho ${ }^{1}$, Natália Deniz Brito ${ }^{2}$, Armínio Santos ${ }^{3}$, Quelmo Silva de Novaes ${ }^{3}$.}

1. Doutorando em Agronomia (Fitotecnia) pela Universidade Estadual do Sudoeste da Bahia - UESB, Vitória da Conquista, Brasil (ggomesrocha@hotmail.com)

2. Graduanda em Agronomia pela Universidade Estadual do Sudoeste da Bahia UESB, Vitória da Conquista, Brasil.

3. Professor Doutor do Departamento de Fitotecnia e Zootecnia da Universidade Estadual do Sudoeste da Bahia - UESB, Vitória da Conquista, Brasil.

Recebido em: 22/09/2018 - Aprovado em: 23/11/2018 - Publicado em: 03/12/2018 DOI: 10.18677/EnciBio_2018B12

\section{RESUMO}

Devido à ausência de medidas efetivas de controle químico para a podridão do colo e raízes do maracujazeiro, causada por Fusarium solani, os agentes biocontroladores surgem como importantes aliados para o manejo desta doença. Assim, objetivou-se com o presente estudo, avaliar a atividade antagonista in vitro de Bacillus subtilis contra isolados de F. solani, por diferentes métodos. Para isso, dois isolados de $F$. solani foram obtidos a partir de plantas de maracujazeiros doentes nas cidades de Anagé e Dom Basílio - BA e um isolado de $B$. subtilis obtido a partir do produto comercial Serenade $\AA$. A atividade antagonista foi avaliada por quatro métodos: cultura pareada, cultura do patógeno sobre cultura do antagonista, metabólitos voláteis e metabólitos termoestáveis, sendo estes comparados a um tratamento controle. O delineamento experimental foi o inteiramente casualizado, arranjo fatorial $2 \times 5$, com cinco repetições. As avaliações foram realizadas medindo o diâmetro médio das colônias de $F$. solani, após oito dias de incubação em câmara de crescimento. Os dados foram submetidos à análise de variância e as médias comparadas pelo teste Scott-Knott, a $5 \%$ de probabilidade. O crescimento micelial de $F$. solani, isolado Anagé, foi inibido significativamente por $B$. subtilis em todos os métodos testados. Quanto ao F. solani, isolado Dom Basílio, seu crescimento micelial foi inibido pelo $B$. subtilis por três métodos, exceto por metabólitos voláteis. O crescimento micelial de $F$. solani, isolado de maracujazeiros, é inibido por $B$. subtilis, representando este, um potencial agente biocontrolador da podridão do colo e raízes do maracujazeiro em campo.

PALAVRAS-CHAVE: Controle biológico, metabólitos voláteis, metabólitos termoestáveis.

\section{ANTIGONIST ACTIVITY OF Bacillus subtilis ON TWO ISOLATES OF Fusarium solani OF MARACUJAZEIRO, BY DIFFERENT METHODS}

\section{ABSTRACT}

Due to the absence of effective chemical control measures for the coleoptile and rot of passion fruit, caused by Fusarium solani, biocontrol agents appear as important allies for the management of this disease. Thus, the objective of the present study was to evaluate the in vitro antagonistic activity of Bacillus subtilis against isolates of $F$. solani, by different methods. For this, two isolates of $F$. solani were obtained from 
diseased passion fruit plants in the cities of Anagé and Dom Basílio - BA and one isolate of $B$. subtilis obtained from commercial product Serenade®. The antagonist activity was evaluated by four methods: paired culture, culture of the pathogen on the antagonist culture, volatile metabolites and thermostable metabolites, being these compared to a control treatment. The experimental design was the completely randomized, at $2 \times 5$ factorial arrangements, with five replicates. The evaluations were performed by measuring the mean diameter of $F$. solani colonies after eight days of incubation in a growth chamber. The data were submitted to analysis of variance and the measures compared by the Scott-Knott test, at $5 \%$ probability. The mycelial growth of $F$. solani, isolated Anagé, was significantly inhibited by $B$. subtilis in all methods tested. As for $F$. solani, Dom Basílio isolated, its mycelial growth was inhibited by $B$. subtilis by three methods, except for volatile metabolites. The mycelial growth of $F$. solani, isolated from passion fruit, is inhibited by $B$. subtilis, representing this, potential biocontrol agent of the collar rot of passion fruit.

KEYWORDS: Biological control, volatile metabolites, thermostable metabolites.

\section{INTRODUÇÃO}

O Brasil é o maior produtor e consumidor mundial de maracujá, sendo o maracujá-amarelo (Passiflora edulis Sims), a espécie mais cultivada em todo o país (FALEIRO; JUNQUEIRA, 2016). O estado da Bahia, com destaque para as cidades de Livramento de Nossa Senhora e Dom Basílio, é o maior produtor nacional desta fruta, respondendo, no ano de 2016, por $49 \%$ das 703 mil toneladas de maracujá produzidas no Brasil (IBGE, 2016). No entanto, um último levantamento realizado pelo IBGE (2018), mostra que a produção nacional e baiana de maracujá no ano de 2017 foi reduzida em 20 e 50\%, respectivamente, em comparação com o ano anterior.

Entraves na produtividade dos cultivos comerciais do maracujá estão associados a problemas fitossanitários que ocorrem na maioria dos pomares brasileiros. As doenças são as principais dificuldades enfrentadas na cultura, provocando quedas significativas na produção, podendo inviabilizar economicamente os cultivos (FISCHER; REZENDE, 2008; MELETTI, 2011).

A doença causada pelo fungo Fusarium solani (Mart.) Sacc., conhecida como podridão do colo e raízes, é descrita como uma das principais doenças que afetam o sistema radicular do maracujazeiro (SILVA et al., 2014). A sintomatologia da podridão do colo e raízes inicia-se com lesões no colo da planta, evoluindo para podridões de todo o sistema radicular, refletindo na parte aérea na forma de murcha de ramos e amarelecimento, podendo causar a morte da planta (FISCHER et al., 2010).

Segundo Rocha Sobrinho et al. (2016), medidas efetivas de controle para a podridão do colo e raízes do maracujazeiro ainda são inexistentes. Contudo, recentemente, espécies silvestres de passiflora vêm sendo testadas como porta enxerto na tentativa de produzir mudas de maracujá-amarelo resistente ou tolerante à podridão do colo e raízes. No entanto, os testes realizados com Passiflora gibertii, Passiflora cincinnata e Passiflora alata não apontaram tolerância a esta doença, sendo a suscetibilidade similar à apresentada pelo próprio maracujá-amarelo (SANTOS et al., 2016).

Em um estudo realizado por Silva et al. (2014), foi demostrado êxito na inibição do crescimento micelial de $F$. solani, isolado de maracujazeiro, por meio da da utilização de espécies de fungos do gênero Trichoderma,que possuem ação como: parasitismo, antibiose e competição. Os resultados obtidos por estes autores 
geraram possibilidades quanto ao uso de agentes biocontroladores para o manejo desta doença em campo.

O controle biológico é um método que consiste no uso de agentes biológicos não patogênicos para controle de fitopatógenos (BRAGA JUNIOR et al., 2017). As bactérias do gênero Bacillus, como a espécie $B$. subtilis, estão sendo estudadas para o biocontrole devido aos seus eficientes mecanismos de antagonismo e amplo espectro de ação contra fitopatógenos (SAJITHA et al., 2017).

Nesse sentido, com o presente estudo, objetivou-se avaliar a atividade antagonista in vitro do Bacillus subtilis contra dois isolados do fungo fitopatogênico $F$. solani, por diferentes métodos, tendo em vista seu grande potencial no controle de doenças fúngicas em plantas.

\section{MATERIAL E MÉTODOS}

O experimento foi conduzido no Laboratório de Fitopatologia da Universidade Estadual do Sudoeste da Bahia - UESB, campus de Vitória da Conquista, durante o segundo semestre de 2018. A atividade antagonista de Bacillus subtilis foi testada para dois isolados do fungo Fusarium solani, por quatro diferentes métodos.

Os isolados de F. solani foram obtidos a partir de plantas de maracujazeiros apresentando sintomas de podridão do colo e raízes, coletadas em dois plantios comerciais, localizados nas cidades de Anagé e Dom Basílio, ambas situadas no Estado da Bahia. Após coletadas, as plantas foram levadas ao laboratório de Fitopatologia da UESB onde procedeu-se com o isolamento dos fungos conforme metodologia descrita por Alfenas et al. (2016) para isolamento de fungos fitopatogênicos. A identificação dos fungos foi realizada conforme chave de classificação descrita por Barnett e Hunter (1972).

$O$ isolado da bactéria $B$. subtilis, utilizado como antagonista foi obtido a partir do produto comercial: Serenade ${ }^{\circledR}$. No primeiro método utilizou-se a técnica de cultura pareada. Nesta técnica, um disco de meio Batata Dextrose Ágar (BDA), medindo $7 \mathrm{~mm}$ de diâmetro, colonizado pelo fungo $F$. solani, foi colocado a $1,5 \mathrm{~cm}$ de distância da borda esquerda de uma placa de petri de $9 \mathrm{~cm}$ de diâmetro, contendo $20 \mathrm{ml}$ de meio BDA e, com o auxílio de uma alça de platina, uma estria de $B$. subtilis foi feita do lado direito, a $1,5 \mathrm{~cm}$ de distância da borda da placa.

Um segundo método consistiu no cultivo do patógeno sobre a cultura do antagonista. Para isto, um disco de $7 \mathrm{~mm}$ de BDA, colonizado por $F$. solani foi alocado no centro da placa de petri, previamente estriadas com $B$. subtilis. Em um terceiro método, avaliou-se a a inibição do crescimento de $F$. solani por meio da produção de metabolitos termoestáveis por B. subtilis. Para tanto, placas de petri, contendo $20 \mathrm{ml}$ de BDA, foram estriadas com $B$. subtilis e incubadas em câmara de germinação por 48 horas. Após este período as placas foram autoclavadas a $121^{\circ} \mathrm{C}$ por 15 minutos e em seguida acondicionadas em câmara de fluxo laminar para solidificação do meio em ambiente asséptico. Após a solidificação do meio, discos de BDA colonizados por $F$. solani foram colocados no centro das placas para posterior avaliação do crescimento.

No quarto método, a atividade antagonista foi avaliada por meio da produção de metabólitos voláteis. Este método consistiu na sobreposição de bases de placas de petri, contendo meio BDA, inoculado com discos de meio BDA, medindo $7 \mathrm{~mm}$ de diâmetro, colonizado por $F$. solani, sobre bases de placas de petri, contendo meio BDA, estriado com $B$. subtilis.

Como tratamento controle, discos de meio BDA, colonizados pelos isolados de $F$. solani, foram adicionados no centro de placas de petri contendo meio BDA. 
Todos os tratamentos foram acondicionados em câmara crescimento, com temperatura constante de $25^{\circ} \mathrm{C}$ e fotoperíodo de 12 horas.

A avaliação consistiu em medir, como o auxílio de uma régua milimetrada, o diâmetro médio das colônias de $F$. solani, oito dias após as inoculações, período em que, um dos isolados, no tratamento controle, atingiu as bordas das placas. Logo após, foi calculada a percentagem de inibição (\%l) de $F$. solani dos tratamentos em relação à testemunha, utilizando a fórmula: $\%=(C-T) / C \times 100$. Onde $\%$ : percentagem de inibição, $\mathrm{C}$ : diâmetro médio do crescimento micelial da testemunha, e T: diâmetro médio do crescimento micelial do tratamento.

O delineamento experimental utilizado foi o inteiramente casualizado (DIC), em arranjo fatorial $2 \times 5$ (dois isolados de $F$. solani, quatro métodos de avaliação do antagonismo + um tratamento controle) com cinco repetições. Os dados foram submetidos à análise de variância, e as médias comparadas pelo teste Scott-Knott, a $5 \%$ de probabilidade, com o auxílio do programa SISVAR (FERREIRA, 2014).

\section{RESULTADOS E DISCUSSÃO}

A análise de variância dos dados do presente trabalho apontou diferença significativa entre os isolados, os métodos e na interação entre os isolados e os métodos. Devido a significância da interação, apenas esta foi desdobrada e os resultados expressos na Tabela 1.

O crescimento micelial dos dois isolados de Fusarium solani testados neste experimento foi inibido significativamente por $B$. subtilis, quando comparados ao tratamento controle (livre crescimento).

TABELA 1. Média de crescimento micelial e porcentagem de inibição de Fusarium solani, submetido a diferentes métodos de antagonismo por Bacillus subtilis.

\begin{tabular}{ccccc} 
& \multicolumn{2}{c}{ Anagé } & \multicolumn{2}{c}{ Dom Basílio } \\
\cline { 2 - 5 } & $\begin{array}{c}\text { Diâmetro } \\
\text { médio }\end{array}$ & \% de inibição & $\begin{array}{c}\text { Diâmetro } \\
\text { médio }\end{array}$ & \% de inibição \\
\hline Cultura pareada & $5,50 \mathrm{Bb}$ & 38,9 & $6,90 \mathrm{Ab}$ & 1,6 \\
$\begin{array}{c}\text { Livre crescimento } \\
\text { Metabólitos }\end{array}$ & $9,00 \mathrm{Ad}$ & - & $7,01 \mathrm{Bc}$ & - \\
$\begin{array}{c}\text { Termoestáveis } \\
\text { Metabólitos Voláteis } \\
\begin{array}{c}\text { Patógeno sobre } \\
\text { antagonista }\end{array}\end{array}$ & $1,65 \mathrm{Aa}$ & 81,7 & $1,53 \mathrm{Aa}$ & 78,2 \\
\hline CV=7,72. & $1,51 \mathrm{Aa}$ & 83,2 & $1,23 \mathrm{Aa}$ & 82,4 \\
\hline
\end{tabular}

Letras iguais maiúscula na linha e minúscula na coluna não diferem entre si pelo teste Skott - Knott a 5 \% de significância.

Os métodos de antagonismo em que $B$. subtilis promoveu as maiores porcentagens de inibição do crescimento micelial dos isolados de $F$. solani foi por metabólitos termoestáveis: 81,7 e $78,2 \%$ para os isolados Anagé e Dom Basílio, respectivamente e por cultura do patógeno sobre cultura do antagonista: 83,2 e $82,4 \%$, isolados Anagé e Dom Basílio, respectivamente (TABELA 1; FIGURA1). 


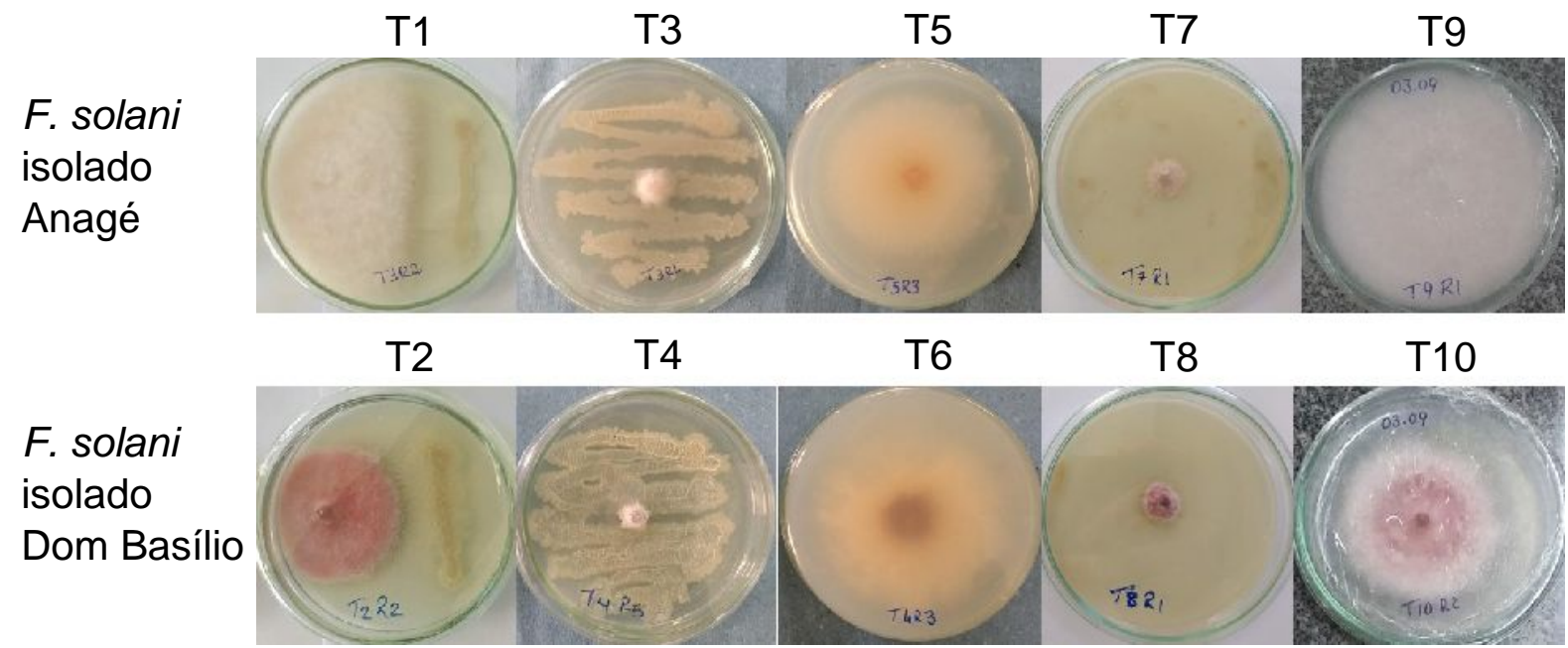

FIGURA 1. Antagonismo entre Bacillus subtilis e Fusarium solani do maracujazeiro, isolados Anagé e Dom Basílio, após oito dias de incubação em câmara de crescimento, por cultura pareada (T1 e T2), cultura do patógeno sobre cultura do antagonista (T3 e T4), metabólitos voláteis (T5 e T6), metabólitos termoestáveis (T7 e T8) e livre crescimento (tratamento controle) (T9 e T10).

O F. solani, isolado Anagé, teve seu crescimento micelial inibido por $B$. subtilis, em todos os métodos testados. Estes resultados corroboram as diversas formas de ação de $B$. subtilis como antagonista a fungos fitopatogênicos já relatadas também por Leelasuphakul et al. (2008). Estes autores observaram a ação de $B$. subtilis pela produção de metabólitos antibióticos orgânicos voláteis, metabólitos antibióticos solúveis em água e proteínas com ação antifúngica na germinação de esporos de Penicillium digitatum.

$O$ B. subtilis mostrou-se eficiente também como antagonista ao $F$. solani, isolado Dom Basílio. O crescimento micelial deste isolado foi inibido por três métodos: cultura pareada, cultura do patógeno sobre cultura do antagonista e por metabólitos termoestáveis. Não houve inibição do crescimento micelial deste isolado por metabólitos voláteis. É possível inferir que houve variações na sensibilidade dos isolados de $F$. solani aos metabólitos voláteis produzidos por $B$. subtilis, uma vez que existe alta variabilidade genética entre isolados de $F$. solani, como já relatada por Dariva et al. (2015), o que pode conferir características distintas entre os isolados de F. solani.

Os metabólitos produzidos por $B$. subtilis apresentaram estabilidade térmica mesmo após serem expostos a $121^{\circ} \mathrm{C}$ de temperatura por 15 minutos, mantendo suas características antifúngicas inalteradas, sendo considerados metabólitos termoestáveis.

A ação antagônica de $B$. subtilis pela produção de metabólitos termoestáveis, assim como observada no presente estudo, também foi relatada por outros autores (BRAGA JUNIOR et al., 2017; PAN et al., 2015; FUGA et al., 2016; AMARO et al., 2018). Estes autores observaram uma redução significativa do crescimento micelial de diversos fungos fitopatogênicos pela ação de metabólitos termoestáveis produzidos por $B$. subtilis.

A produção de metabólitos termoestáveis constitui-se uma característica de suma importância para um microrganismo a ser utilizado no biocontrole de doenças radiculares. Pois, para Bettiol e Ghini (2009), as mudanças climáticas interferem ENCICLOPÉDIA BIOSFERA, Centro Científico Conhecer - Goiânia, v. 15 n.28; p.135 2018 
consideravelmente na estabilidade e produção de metabólitos por agentes biocontroladores de doenças de plantas. Assim, a estabilidade térmica dos compostos antibióticos liberados por $B$. subtilis lhe garante vantagem no antagonismo contra fitopatógenos, também habitantes naturais de solo, como é o caso de F. solani.

\section{CONCLUSÃO}

A bactéria Bacillus subtilis inibe o crescimento micelial de Fusarium solani, isolado de maracujazeiros, pela produção de metabólitos voláteis e não voláteis termoestáveis, se destacando como um potencial agente biocontrolador da podridão do colo e raízes desta cultura em campo.

\section{REFERÊNCIAS}

ALFENAS, A.C.; FERREIRA, F.A.; MAFIA, R.G. GONÇALVES, R.C. Isolamento de fungos fitopatogênicos. In: ALFENAS, A.C.; MAFIA, R.G. Métodos em Fitopatologia. 2 ed. Viçosa, MG. UFV. p. 55-92. 2016.

AMARO, J.K.C.; VIEIRA, B.S.; SOUSA, L.A. BIOLOGICAL CONTROL OF Colletotrichum gloeosporioides IN PEPPER WITH ISOLATES OF Bacillus subtilis. Brazilian Journal of Agriculture -Revista de Agricultura, v. 93, n. 2, p. 195-209, 2018. Disponível em: $<$ http://www.revistadeagricultura.inf.br/index.php/revistadeagricultura/article/view/329 9>.

BARNETT, H.L.; HUNTER, B.B. Illustrated genera of imperfect fungi. $3^{\underline{a}}$ ed. Minneapolis. Burgess Publishing Company. 1972.

BETTIOL, W.; GHINI, R. Impacto das mudanças climáticas sobre o controle biológico de doenças de plantas. In: Biocontrole de doenças de plantas: uso e perspectivas. Jaguariuna: Embrapa Meio Ambiente, 2009. p. 29-48. Disponível em: > $<$ https://www.embrapa.br/busca-de-publicacoes/-/publicacao/579954/biocontrole-dedoencas-de-plantas-uso-e-perspectivas >.

BRAGA JUNIOR, G.M.; CHAGAS JUNIOR, A.F.; CHAGAS, L.F.B.; CARVALHO FILHO. M.R.; MILLER, L.O.; SANTOS, G.R. Controle biológico de fitopatógenos por Bacillus subtilis in vitro. Biota Amazônia (Biote Amazonie, Biota Amazonia, Amazonian Biota), v. 7, n. 3, p. 45-51, 2017. Disponível em: <http://periodicos.unifap.br/index.php/biota>. DOI: http://dx.doi.org/10.18561/21795746/biotaamazonia.v7n3p45-51.

DARIVA, J.C.; XAVIER, A.A.; COSTA, M.R.; RIBEIRO, R.C.F.; SOUSA, T.V. Variabilidade genética de isolados de Fusarium solani e Fusarium oxysporum f. $\mathrm{sp}$. passiflorae associados ao maracujazeiro. Revista Brasileira de Fruticultura, Jaboticabal, v. 37, n. 2, p. 377-386, 2015. Disponível em: < http://www.scielo.br/pdf/rbf/v37n2/0100-2945-RBF-37-2-377.pdf>. http://dx.doi.org/10.1590/0100-2945-119/14.

FALEIRO, F.G.; JUNQUEIRA, N.T.V. Maracujá: o produtor pergunta, a Embrapa responde. Embrapa Cerrados-Livro técnico (INFOTECA-E), 2016. Disponível 
em:< https://www.embrapa.br/busca-de-publicacoes/-/publicacao/1061917/maracujao-produtor-pergunta-a-embrapa-responde>.

FERREIRA, D.F. Sisvar: a Guide for its Bootstrap procedures in multiple comparisons. Ciência e Agrotecnologia. [online]. 2014, vol.38, n.2 [citado 2015-1017], pp. 109-112 . Disponible en: ISSN 1413-7054. DOI: http://dx.doi.org/10.1590/S1413-70542014000200001.

FISCHER, I. H.; REZENDE, J. A. M. Diseases os passion flower (Passiflora spp.). Pest technology, v. 2, n. 1, p. 1-19, 2008. Disponível em: < https://www.researchgate.net/profile/lvan_Fischer/publication/228483390_Diseases_ of_Passion_flower_Passiflora_spp/links/0f31753282313adf5e000000.pdf >.

FISCHER, I. H; BUENO, C. J; DE MARCHI GARCIA, M. J; MARQUES DE ALMEIDA, A. Reação de maracujazeiro-amarelo ao complexo fusariose-nematoide de galha. Acta Scientiarum Agronomy, v. 32, n. 2, 2010. Disponível em: <http://periodicos.uem.br/ojs/index.php/ActaSciAgron/article/view/3445/3445>. DOI: http://dx.doi.org/10.4025/actasciagron.v32i2.3445.

FUGA, C.A.G.; LOPES, E.A.; VIEIRA, B.S.; CUNHA, W.V. Efficiency and compatibility of Trichoderma spp. and Bacillus spp. isolates on the inhibition of Sclerotium cepivorum. Científica, v. 44, n. 4, p. 526-531, 2016. Disponível em: < http://cientifica.org.br/index.php/cientifica/article/view/897>. http://dx.doi.org/10.15361/1984-5529.2016v44n4p526-531.

DOI:

IBGE. Produção agrícola municipal: culturas temporárias e permanentes. Rio de Janeiro: IBGE, 2016. v. 43, 62 p. Disponível em: $<$ https://loja.ibge.gov.br/agropecuaria-196/producao-agropecuaria>. Acesso em: 15.set. 2018.

IBGE. Produção agrícola municipal: culturas temporárias e permanentes. Rio de Janeiro: IBGE, 2018. v. 44. Disponível em: <http://www.sidra.ibge.gov.br>. Acesso em: 18.set. 2018.

LEELASUPHAKUL, W.; HEMMANEE, P.; CHUENCHITT, S. Samerchai. Growth inhibitory properties of Bacillus subtilis strains and their metabolites against the green mold pathogen (Penicillium digitatum Sacc.) of citrus fruit. Postharvest biology and Technology, v. 48, n. 1, p. 113-121, 2008. Disponível em: < https://www.sciencedirect.com/science/article/pii/S0925521407003043>

DOI:10.1016/j.postharvbio.2007.09.024.

MELETTI, L.M.M. Avanços na cultura do maracujá no Brasil. Revista Brasileira de Fruticultura, v. 33, n. SPE1, p. 83-91, 2011. Disponível em: < http://www.scielo.br/pdf/rbf/v33nspe1/a12v33nspe1.pdf>. http://dx.doi.org/10.1590/S0100-29452011000500012.

PAN, D.; MIONETTO, A.; TISCORNIA, S.; BETTUCCI, L. Endophytic bacteria from wheat grain as biocontrol agents of Fusarium graminearum and deoxynivalenol production in wheat. Mycotoxin research, v. 31, n. 3, p. 137-143, 2015. Disponível 
em: <https://link.springer.com/article/10.1007/s12550-015-0224-8>. DOI: 10.1007/s12550-015-0224-8.

ROCHA SOBRINHO, G.G.; RODRIGUES, G.B; SANTOS, A.; JESUS JUNIOR, W.C; NOVAES, Q.S. (2016). Efeito de fosfito de potássio no crescimento e na densidade micelial do Fusarium solani do maracujazeiro. Summa Phytopathologica, v. 42, n. 2, $\quad$ p. 180-182, 2016.2 Disponível em: <180182.http://www.scielo.br/pdf/sp/v42n2/0100-5405-sp-42-2-0180.pdf>. $\quad$ DOI: http://dx.doi.org/10.1590/0100-5405/2139.

SAJITHA, K.L.; DEV, S.A.; FLORENCE, E.J.M. Biocontrol potential of Bacillus subtilis B1 against sapstain fungus in rubber wood. European journal of plant pathology, v. 150, n. 1, p. 237-244, 2017. Disponível em: < https://link.springer.com/article/10.1007/s10658-017-1272-z>. DOI: 10.1007/s10658017-1272-z.

SANTOS, C.H.B.; OLIVEIRA, E.J.D.; LARANJEIRA, F.F.; JESUS, O.N.D.; GIRARDI, E.A.L. Growth, fruit set, and fusariosis reaction of yellow passion fruit grafted onto passiflora spp. Revista Brasileira de Fruticultura, v. 38, n. 3, 2016. Disponível em: <http://www.scielo.br/pdf/rbf/v38n3/0100-2945-rbf-38-3-e-711.pdf>. http://dx.doi.org/10.1590/0100-29452016711.

SILVA, A.N.; AZEVEDO, G.B.; ROCHA SOBRINHO, G.G.; NOVAES, Q.S. Efeito de produtos químicos e de Trichoderma spp. no controle de Fusarium solani do maracujazeiro. Interciencia, v. 39, n. 6, p. 398, 2014. Disponível em: $<$ https://www.interciencia.net/wp-content/uploads/2017/11/398-c-NOVAES-6.pdf>. 